\title{
PADRÃO-POLÍTICA: fincando prioridade e propriedade no terreno educacional
}

\author{
Rita de Cassia Prazeres Frangella \\ Universidade do Estado do Rio de Janeiro - UERJ
}

\begin{abstract}
Resumo
Este artigo objetiva discutir a perspectiva de padronização/estandardização que se observa nas políticas públicas curriculares contemporâneas, argumentando que elas se erigem como padrões utilizando como metáfora os marcos do Descobrimento utilizados pela Coroa Portuguesa em sua expansão ultramarina. Estabelecer a relação entre os padrões históricos e a tomada da política como padrão alude a uma perspectiva de homogeneização. Problematiza-se a defesa da ideia de que é possível a definição de marcos precisos para delimitar o que é, para que serve e o que contém o currículo, na definição do que é política-padrão. Nessa linha argumentativa, conhecimentos padrão são definidos com precisão na valoração dos conhecimentos científicos, que tem seguido um percurso também de polarização entre ciência e cultura. Defende-se política curricular como política cultural e, a partir de diálogos com aportes pós-coloniais e pósfundacionais, do conhecimento como estereótipo e fetiche.
\end{abstract}

Palavras-chave: Política curricular; Conhecimento; Cultura; Discurso; Estereótipo.

\begin{abstract}
This article aims to discuss the perspective of uniformity/standardization that is observed in contemporary curricular public policies, arguing that these stand as standards, using as a metaphor the marks of discovery used by the Portuguese Crown in its overseas expansion. Establishing the relationship between historical patterns and policy making as a pattern alludes to a homogenization perspective. The defense of the idea that it is possible to define precise milestones to delimit what is, what is used for and what the curriculum contains in the definition of what is standard policy is problematized. In this line of argument, standard knowledge is precisely defined in the valuation of scientific knowledge that has also followed a path of polarization between science and culture. Curricular policy is defended as cultural policy and, from dialogues with postcolonial and post-foundational contributions, knowledge as stereotype and fetish.
\end{abstract}

Key-words: curriculum policy; knowledge; culture; discourse; stereotype. 


\section{Nota preliminar: acerca de padrões}

Para iniciar a reflexão, preciso tecer uma breve conversa com os leitores possíveis deste texto. Ainda que não se preste a isso, preciso esclarecer a metáfora/símbolo a que recorro para desenvolver o texto e, com isso, expor seu traçado/objetivo: pôr em pauta uma perspectiva de padronização/estandardização que se observa nas políticas públicas educacionais, focalizando as políticas curriculares. Assim, questiono como elas se erigem como "padrões" e aqui uso o duplo sentido que a palavra suscita e a simbologia que ela evoca: como objeto histórico, padrão é o nome dado ao marco posto pelos navegadores portugueses nos territórios em que aportavam, como símbolo de prioridade e propriedade sobre aquele espaço que estaria, a partir de então, sob a égide da coroa portuguesa ${ }^{1}$.

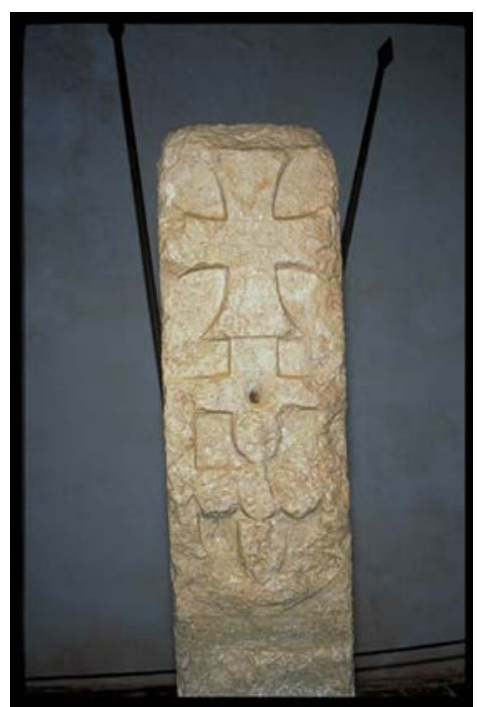

Marco Quinhentista - Natal/RN.

Fonte: Fototeca/Iphan -http://portal.iphan.gov.br/galeria/detalhes/178?eFototeca=1. Acesso em: set/2019.

Tais marcos foram comuns no Brasil, como o Marco Quinhentista dos Touros, que está no Forte dos Reis Magos, em Natal/RN, data de 1501 e é considerado pelo Instituto do Patrimônio Histórico e Artístico Nacional/Iphan o monumento histórico preservado mais antigo do país².

Essa nota preliminar me permite também referenciar Fernando Pessoa e sua poesia Mensagem, originalmente publicada em 1934, que tem como temática a constituição de uma portugalidade assentada nos feitos dos heróis navegadores e da coroa. Dividido em três partes, iniciado com expressões em latim, trata de símbolos e faz (também) uso de nota preliminar para esclarecer essa opção e adverte sobre a necessidade de algumas condições aos leitores, "sem as quais os símbolos serão para ele mortos, e ele um morto para eles".

É aí que encontro o "Padrão" - título de um poema que compõe a primeira parte do livro (Brasão) e que fala do navegador Diogo Cão, que fincou os primeiros padrões da coroa Portuguesa em África, em 1482. 
O esforço é grande e o homem é pequeno.

Eu, Diogo Cão, navegador, deixei Este padrão ao pé do areal moreno

E para deante naveguei.

A alma é divina e a obra é imperfeita.

Este padrão signala ao vento e aos céus Que, da obra ousada, é minha a parte feita:

O por-fazer é só com Deus.

E ao imenso e possível oceano

Ensinam estas Quinas, que aqui vês,

Que o mar com fim será grego ou romano:

O mar sem fim é portuguez.

E a cruz ao alto diz que o que me ha na alma

E faz a febre em mim de navegar

Só encontrará de Deus na eterna calma O porto sempre por achar (Pessoa, 2010, p. 77).

Que padrões estão sendo fincados no terreno educacional? Que prioridades se definem e demarcam um dado domínio e que sentidos são imputados com isso?

\section{Padrão: regulamentação e unificação}

A leitura dessa obra de Fernando Pessoa nos enreda na história entrelaçada de Brasil e Portugal - da chegada em terras longínquas de navegadores que acreditaram que o mar sem fim era de fato português e, para afirmá-lo, delinearam estratégias que demarcassem esse fato.

A história do desenvolvimento da navegação portuguesa passa por diferentes momentos, tendo iniciado, com as viagens de Diogo Cão, sob o reinado de D. João II, um novo período, em que o Estado retoma a coordenação dos avanços marítimos, coordenação que, em período anterior, teve a empresa ultramarina arrendada a um navegante burguês, Fernão Gomes. Assim, para regulamentar a posse das terras descobertas, as embarcações levavam consigo padrões - pilares de pedra com o brasão das armas portuguesas - que, fincados, constituíam ato solene de posse (Bastos, 2012).

Se tomarmos a metáfora como possibilidade de problematização dos marcos fincados na produção de políticas curriculares contemporâneas, podemos também concebê-las como um cenário de estabelecimento de políticas como padrões, como marcos que regulamentam e unificam/uniformizam o currículo no Brasil. Se antes o intento era a constituição de um império português além-mar, hoje essa perspectiva se desloca para a intenção, essa não tão diferente, de controle de forma ampla e irrestrita, a partir da garantia de um lócus central de decisão, da produção/gestão das práticas educacionais, aqui especificamente tratando da 
elaboração/definição de uma Base Nacional Comum Curricular - BNCC. No documento que apresenta a segunda versão da Base $(2016)^{3}$, afirma-se:

As quatro políticas que decorrem da BNCC - Política Nacional de Formação de Professores, Política Nacional de Materiais e Tecnologias Educacionais, Política Nacional de Avaliação da Educação Básica e Política Nacional de Infraestrutura Escolar - articulam-se para garantir as condições que geram a qualidade na Educação Básica, ou seja, o direito de aprender e de se desenvolver dos/das estudantes da Educação Básica, acolhidos em sua diversidade e em uma perspectiva inclusiva. Desse modo, a existência de uma base comum para os currículos demandará ações articuladas das políticas dela decorrentes, sem as quais ela não cumprirá seu papel de contribuir para a melhoria da qualidade da Educação Básica brasileira e para a construção de um Sistema Nacional de Educação (Brasil, 2016, p. 27).

O trecho explicita a condição da BNCC como marco/padrão a partir do qual se desenvolverá a constituição das políticas educacionais. Isso fica ainda mais evidente na terceira versão da BNCC (2017), quando se afirma:

A Base Nacional Comum Curricular (BNCC) é um documento de caráter normativo que define o conjunto orgânico e progressivo de aprendizagens essenciais que todos os alunos devem desenvolver ao longo das etapas e modalidades da Educação Básica (p. 7).

[...] Referência nacional para a formulação dos currículos dos sistemas e das redes escolares dos Estados, do Distrito Federal e dos Municípios e das propostas pedagógicas das instituições escolares, a BNCC integra a Política Nacional da Educação Básica e vai contribuir para o alinhamento de outras políticas e ações, em âmbito federal, estadual e municipal, referentes à formação de professores, à avaliação, à elaboração de conteúdos educacionais e aos critérios para a oferta de infraestrutura adequada para o pleno desenvolvimento da educação (p. 8, grifo nosso).

Essa redação foi mantida na BNCC que foi homologada pelo Conselho Nacional de Educação/CNE em dezembro de 2017 (Brasil, 2018). A apresentação da BNCC homologada reforça a ideia do marco-padrão:

É com muita satisfação que apresentamos o resultado desse grande avanço para a educação brasileira. A BNCC é um documento plural, contemporâneo, e estabelece com clareza o conjunto de aprendizagens essenciais e indispensáveis a que todos os estudantes, crianças, jovens e adultos, têm direito. Com ela, redes de ensino e instituições escolares públicas e particulares passam a ter uma referência nacional obrigatória para a elaboração ou adequação de seus currículos e propostas pedagógicas. Essa referência é o ponto ao qual se quer chegar em cada etapa da Educação Básica, enquanto os currículos traçam o caminho até lá (Brasil, 2018, p. 5, grifos próprios). 
Se tal leitura pode parecer radical num primeiro momento, desbravar, como os navegadores, o mar bravio que a metáfora escolhida apresenta não se trata de cingir águas rasas.

Seed (1999), em obra que analisa as cerimônias de posse na conquista do novo mundo pelos europeus, faz um estudo comparado entre cinco potências colonizadoras e as diferenças entre suas cerimônias de posse que desencadearam diferentes colonizações e conflitos. No caso português, refere-se à importância dos marcos/padrões portugueses associados ao sentido de descoberta - os portugueses detinham o conhecimento, a tecnologia e o avanço científico de conhecimentos astronômicos. Defendiam a posse com base em uma ideia de descoberta assentada no domínio do conhecimento que os permitiu navegar. O poderio português era expresso nos padrões assentados que, mais que marcar a passagem dos portugueses naquelas terras, eram símbolos de um feito tecnológico - não só a conquista e domínio de novas terras, mas o domínio de um novo céu e novas estrelas que, a partir do conhecimento astronômico desenvolvido, permitiam descrever um local com precisão, com o uso de latitude (p. 176), o que também possibilitou que Portugal tivesse o domínio da navegação em alto-mar até 1530.

Era a descoberta via conhecimento que demarcava a posse. A prioridade portuguesa se dava baseado em um conhecimento dominado. Em suas análises, Seed (apud Kalil e Fernandes, 2014) também destaca uma dimensão importante a partir dessas cerimônias de posse: a linguagem e as iniciativas de colonização. O domínio da terra descoberta desembocou num processo de homogeneização: o objetivo de colonizar exerceu poderosa força coercitiva que impeliu a necessidade de fixar, ou melhor, na afirmação da autora, inventar uma identidade linguística e legal que fosse "inglesa" ou "portuguesa" com fins de colonizar (p. 412).

Nesse entrecruzamento da questão do domínio de um conhecimento como justificação para posse e a necessidade de homogeneizar que efetivasse essa conquista, podemos discutir também como o conhecimento justifica a própria homogeneização. Daí que estabelecer a relação entre os padrões históricos e a tomada da política como padrão alude a uma perspectiva de homogeneização.

Essa linha argumentativa me permite qualificar a BNCC como política-padrão e que a partir das perspectivas em que tenho assentado meus trabalhos - a defesa de uma perspectiva do currículo como produção cultural, enunciação rasurada pela diferença (Frangella, 2016a) - problematizo, questionando o atrelamento da posse do conhecimento como processo de uniformização homogeneizante.

\section{Conhecimento, cultura e homogeneização - colonização a partir de "dentro"}

Minha problematização acerca do que nomeei como política-padrão exige discutir a defesa da ideia de que é possível a definição de marcos precisos para delimitar o que é, para que serve e o que contém o currículo. 
Trata-se de um argumento que vem sendo desenvolvido a partir da noção de que a função precípua do currículo é a aquisição de conhecimento; então, ele deveria ser visto como princípio curricular, o que se desenvolve na crítica que afirma haver

um ceticismo em relação ao conhecimento, entretanto, permaneceu vivo nos debates abstratos e esotéricos associados com os estudos culturais e as ciências sociais e suas asserções de que não existe essa verdade ou esse "conhecimento objetivo". Além disso, essas suposições tornaram-se amplamente aceitas nos estudos educacionais - frequentemente transbordando para a minha própria disciplina, a Sociologia da Educação. "Todo conhecimento, conhecimento situado, que reflete a posição do seu produtor ou conhecedor, em um determinado momento histórico, em um dado contexto cultural” (Lennon, 2010, p. 376, tradução nossa), é assim que a filósofa americana Kathleen Lennon coloca a questão, por exemplo. Mas a sua afirmação não é excepcional, de forma alguma. Se todo conhecimento está situado em um contexto, isso leva a um relativismo que rejeita a suposição de haver um conhecimento "melhor" em qualquer área, que poderia ou deveria embasar o currículo escolar. Como consequência, o currículo se torna aberto a toda uma variedade de finalidades outras que não sejam a aquisição de conhecimento (Young, 2016, p. 21).

As afirmações de Young $(2014 ; 2016)$ acerca do conhecimento poderoso como princípio curricular e do que tem discutido como contexto de ataque ou medo do conhecimento, na defesa de uma educação compreensiva para todos, associa a tarefa de elaboração de um currículo que não pode abrir mão de uma perspectiva seletiva à ideia de direito ao conhecimento para todos. $\mathrm{O}$ autor ressalta que se opõe às visões prescritivas e instrumentais, diferenciando uma visão progressivista conservadora de uma visão politicamente conservadora.

A defesa é de que há conhecimentos melhores que outros, ou seja, especializados. Dessa forma, o autor permite um deslizamento para uma ideia de conhecimento objetivo com um contexto de produção "também melhor": o científico. Desdobra-se daí a crítica que faz ao que afirma ser a primazia de uma visão relativista, o que contrapõe à visão que defende: uma perspectiva realista, que também permite o desenvolvimento de uma normatividade calcada em princípios claros e possíveis de serem previamente definidos e controlados.

Nessa linha, o autor argumenta que o medo do conhecimento se manifesta na centralidade dada a aprendizagem:

Uma outra maneira pela qual esse medo do conhecimento se manifesta está na forma pela qual a aprendizagem tomou o lugar da educação em termos de política e linguagem curriculares; por exemplo, temos um módulo no Instituto de Educação da Universidade de Londres denominado Aprendizagem Profissional, e não Educação Profissional. A aprendizagem é considerada aberta, boa, progressivista e criadora de oportunidades para novos aprendizados; por que atrapalhar tudo perguntando o que os estudantes estão aprendendo? A ênfase 
atual está em encorajar os estudantes a estarem sempre abertos a novas oportunidades de aprendizagem - o ubíquo “aprender a aprender" pode, facilmente, fazer com que os estudantes percam a confiança no que já sabem. Se um estudante adquiriu algum conhecimento que o ajuda a entender melhor o mundo, aprender a desprezar esse conhecimento deveria ser difícil, e não fácil (Young, 2016, p. 28).

Contudo, penso que o que o autor afirma como sendo central não é a primazia da aprendizagem na linguagem curricular, mas a dissociação entre aprendizagem e conhecimento. Ao referir-se à substituição da educação por aprendizagem, penso que se refere a conhecimento, uma vez que mais adiante no texto afirma: "educação é o desenvolvimento de uma relação com o conhecimento” (p. 29). Isso também implica um reducionismo improdutivo, uma vez que há um conhecimento melhor, especializado, poderoso. Então, educação é uma relação com esse conhecimento? Esvazia-se a educação de sua multidimensionalidade, de sua dimensão formativa de relações interpessoais, entre outras. Seria então o conhecimento o centro de todo o processo educativo? Reflito sobre isso com Derrida (2011, p. 408): "E ainda hoje uma estrutura privada de centro representa o próprio impensável”.

Lopes (2015), em artigo que intenta debater a ideia de normatividade, argumentando, com base na teoria do discurso de Laclau, a favor da produtividade política de um déficit normativo imputado a enfoques pós-estruturais, traz a questão de como essa ideia de normatividade vem se apresentando no campo do currículo no Brasil. Uma das questões levantadas pela autora trata do que afirma ser uma "redução da política curricular a uma política do conhecimento” (p. 118). Nessa linha, desenvolve a reflexão na análise das proposições de Young, observando que significações são disputadas para o currículo.

Um outro exemplo do "medo do conhecimento" é encontrado quando os educadores são levados a confundir um necessário respeito pelos valores culturais de uma comunidade com a verdade das explicações oferecidas pelas disciplinas escolares. Sociedades multiculturais colocam um grande número de novos problemas para os professores; eles têm que fazer a distinção entre significados "específicos do contexto", que são uma característica de todas as "culturas”, e significados "independentes do contexto", do currículo. Os estudantes podem "conhecer" muito sobre a sua própria cidade, por terem crescido nela; porém, a disciplina Geografia lhes ensina um tipo muito diferente de conhecimento sobre "cidades" - um conhecimento que podem usar para fins de generalização (Young, 2016, p. 29).

Tal afirmativa, assentada na divisão binária que o autor vai desenhando entre conhecimento tácito e conhecimento poderoso, entre o pedagógico e a influência de estudos advindos da área das ciências sociais, entre experiência e conhecimento, foco no conhecedor ou no conhecimento etc., permitem a partir do esvaziamento de uma esfera, 
valorizar a outra em termos de proposições unívocas que possam garantir o "direito de todos ao conhecimento", sendo esse o conhecimento especializado.

No artigo citado, o autor explica a trajetória de suas análises na crítica a um conhecimento dos poderosos até o que atualmente argumenta em defesa de um conhecimento poderoso. Nesse percurso, cita sua experiência de participação em reformulações curriculares na África do Sul pós-apartheid, que se baseava nas proposições de Paulo Freire e depois suas releituras de autores como Vygotsky. Daí afirma:

Quando voltei para a Inglaterra, tive que enfrentar uma série de críticas acadêmicas ao meu primeiro trabalho e comecei a reler as obras de Durkheim, Bernstein e Vygotsky. Foi por meio dessa leitura e da minha experiência na África do Sul que inverti os termos "poder" e "conhecimento": se o conceito original "conhecimento dos poderosos" se tornasse o novo conceito de "conhecimento poderoso", poderíamos ter as bases para fazer um conjunto de perguntas sobre o que seria um currículo que levasse a sério a ideia de "direito para todos”.

[...] A ideia de "conhecimento poderoso" começa com duas afirmações: (i) há um "melhor conhecimento" em todas as áreas; e (ii) a base de todas as decisões sobre conhecimento no currículo é a ideia de diferenciação, de que existem diferentes tipos de conhecimento (Young, 2016, p. 33).

Se tomamos a própria afirmação do autor - “existem diferentes tipos de conhecimento” como premissa e suas próprias referências, no caso, Vygotsky (1993), podemos discutir a associação problemática entre poder e conhecimento, que qualifica a partir daí o conhecimento especializado em detrimento do conhecimento cotidiano.

Vygotsky (1993), ao estudar o desenvolvimento dos conceitos científicos na infância, fá-lo partindo da premissa de que

o desenvolvimento dos conceitos não espontâneos tem que possuir todos os traços peculiares ao pensamento da criança em cada nível do desenvolvimento, porque esses conceitos não são aprendidos mecanicamente, mas evoluem com ajuda de uma vigorosa atividade mental por parte da própria criança. Acreditamos que os dois processos - o desenvolvimento dos conceitos espontâneos e dos conceitos não espontâneos - se relacionam e se influenciam constantemente. Fazem parte de um único processo: o desenvolvimento da formação de conceitos, que é afetado por diferentes condições externas e internas, mas que é essencialmente um processo unitário, e não um conflito entre formas de intelecção antagônicas e mutuamente exclusivas (p. 74).

Para o desenvolvimento da argumentação que faço, destaco alguns aspectos ressaltados por Vygotsky: inicialmente o autor não hierarquiza os conceitos de que trata, menciona espontâneos e não espontâneos, obviamente enfatizando a diferenciação que de fato há entre eles, mas sem que com isso enverede por uma qualificação estratificada deles; chama a atenção de que se trata de um processo unitário, que, se os conceitos não espontâneos não 
são aprendidos mecanicamente, sua transmissão sem observar a relação com conceitos espontâneos é infrutífera, inclusive como explica no desenvolvimento do texto, ressaltando a importância dos conceitos espontâneos para o desenvolvimento dos não espontâneos; não se trata de processos de intelecção antagônicos.

Assim, a partir da defesa de que aprendizagem e desenvolvimento se dão de forma inter-relacionada e interdependente, o autor prossegue na defesa de uma compreensão que não apaga a especificidade do conhecimento científico (foco do estudo que faz) - esse permite a percepção generalizante, o desenvolvimento da consciência reflexiva - e chama a atenção para como conceitos espontâneos e científicos têm papéis complementares e importantes no desenvolvimento mental. Apesar de se desenvolverem em direções distintas, o que se desdobra dos processos que marcam seu "surgimento" - os espontâneos a partir de situações concretas; os científicos, a partir de ação mediada - trata-se de processos implicados um no outro. O autor afirma:

É preciso que o desenvolvimento de um conceito espontâneo tenha alcançado um certo nível para que a criança possa absorver um conceito científico correlato. [...] Ao forçar sua lenta trajetória para cima, um conceito cotidiano abre o caminho para um conceito científico e o seu desenvolvimento descendente. Cria uma série de estruturas necessárias para a evolução dos aspectos mais primitivos e elementares de um conceito, que lhe dão corpo e vitalidade. Os conceitos científicos, por sua vez, fornecem estruturas para o desenvolvimento ascendente dos conceitos espontâneos da criança em relação à consciência e ao uso deliberado. Os conceitos científicos desenvolvem-se para baixo por meio dos conceitos espontâneos; os conceitos espontâneos desenvolvem-se para cima por meio dos conceitos científicos (p. 93-94).

O que merece destaque é que o que se antevê a partir do estudo de Vygotsky sobre o desenvolvimento e a relação com os conceitos científicos; é sua importância, mas não sua exclusividade. Assim, não se observam no estudo do autor menções que, valorativamente, ao qualificar o conhecimento científico, possam servir como índices de desvalorização de outros conhecimentos. Ao contrário, ainda que não explicitamente, o autor chama a atenção para a existência de diferentes conhecimentos; ao tratar mesmo dos conceitos não espontâneos assim o faz mencionando que, dentre esses, destaca os científicos como objeto de estudo.

Numa linha argumentativa diferenciada, Young (2016), ao adjetivar o conhecimento científico como melhor, é que torna a leitura problemática a partir das defesas que faz, uma vez que vai desenhando fronteiras rígidas de polarização que põem o conhecimento científico na centralidade do fazer curricular e de forma hierarquicamente diferenciada em relação a outros conhecimentos.

Argumentos como os apresentados por Young (vale ressaltar que não só por ele), aqui analisados mais detidamente, têm servido de justificativa e defesa em torno do direito de aprendizagem que vemos figurar como elemento articulador nas políticas curriculares em pauta no Brasil, em especial a BNCC. Como já discuti em estudos anteriores (Frangella, 
2016; ; 2016b; Frangella, 2018), a questão que se observa é o deslizamento da defesa do direito à educação ao direito à aprendizagem como estratégia de equidade que se expressaria no acesso a conhecimentos comuns, vistos como fixos, validados, melhores, sendo o conhecimento científico o que prescinde de justificativas e/ou validações outras que indiquem sua relevância e pertinência, por ser melhor, independente do contexto (Young, 2016, p. 33, grifos do autor). Tais argumentos podem ser observados em extratos das diferentes versões da BNCC:

A equidade supõe a igualdade de oportunidades para ingressar, permanecer e aprender na escola, por meio do estabelecimento de um patamar de aprendizagem e desenvolvimento a que todos têm direito. Decorre disso a necessidade de definir, mediante pactuação interfederativa, direitos e objetivos de aprendizagem essenciais a ser alcançados por todos os alunos da Educação Básica. A BNCC vem cumprir esse papel, tendo como foco principal a igualdade e a unidade nacional (BRASIL, BNCC, $3^{\text {a }}$ versão, 2017, p. 11, grifo nosso).

Ao deixar claros os conhecimentos essenciais, a que todos os estudantes brasileiros têm o direito de acesso e de apropriação durante sua trajetória na Educação Básica, desde o ingresso na creche até o final do Ensino Médio, a Base Nacional Comum Curricular (BNCC) constitui-se parte importante do Sistema Nacional de Educação (BRASIL, BNCC, 2 ${ }^{\mathrm{a}}$ versão, 2016, p. 31).

O ponto de partida para a definição dos objetivos de aprendizagem propostos pelo documento preliminar da BNCC são os direitos de aprendizagem apresentados no texto Base Nacional Comum Curricular (BNCC) Princípios orientadores da definição de objetivos de aprendizagem das áreas de conhecimento. Os doze direitos de aprendizagem enunciados no referido texto constituem um conjunto de proposições que orientam as escolhas feitas pelos componentes curriculares na definição de seus objetivos de aprendizagem, consideradas as dimensões ética, estética e política de efetivação daqueles direitos de aprendizagem e desenvolvimento (BRASIL, BNCC, $1^{\text {a }}$ versão, 2015, p 13).

Tal perspectiva pode ser ainda observada no delineamento do que caberia ao currículo expresso na versão homologada da BNCC (2018):

Além disso, BNCC e currículos têm papéis complementares para assegurar as aprendizagens essenciais definidas para cada etapa da Educação Básica, uma vez que tais aprendizagens só se materializam mediante o conjunto de decisões que caracterizam o currículo em ação. São essas decisões que vão adequar as proposições da BNCC à realidade local, considerando a autonomia dos sistemas ou das redes de ensino e das instituições escolares, como também o contexto e as características dos alunos. Essas decisões, que resultam de um processo de 
envolvimento e participação das famílias e da comunidade, referem-se, entre outras ações, a:

- contextualizar os conteúdos dos componentes curriculares, identificando estratégias para apresentá-los, representá-los, exemplificá-los, conectá-los e torná-los significativos, com base na realidade do lugar e do tempo nos quais as aprendizagens estão situadas;

- decidir sobre formas de organização interdisciplinar dos componentes curriculares e fortalecer a competência pedagógica das equipes escolares para adotar estratégias mais dinâmicas, interativas e colaborativas em relação à gestão do ensino e da aprendizagem;

- selecionar e aplicar metodologias e estratégias didático-pedagógicas diversificadas, recorrendo a ritmos diferenciados e a conteúdos complementares, se necessário, para trabalhar com as necessidades de diferentes grupos de alunos, suas famílias e cultura de origem, suas comunidades, seus grupos de socialização etc.;

- conceber e pôr em prática situações e procedimentos para motivar e engajar os alunos nas aprendizagens;

- construir e aplicar procedimentos de avaliação formativa de processo ou de resultado que levem em conta os contextos e a condições de aprendizagem, tomando tais registros como referência para melhorar o desempenho da escola, dos professores dos alunos;

- selecionar, produzir, aplicar e avaliar recursos didáticos e tecnológicos para apoiar o processo de ensinar e aprender;

- criar e disponibilizar materiais de orientação para os professores, que possibilitem contínuo aperfeiçoamento dos processos de sobre gestão pedagógica e curricular para os demais educadores, no âmbito das escolas e sistemas de ensino (Brasil, 2018, p. 16-17).

O longo extrato citado se justifica por apontar a forma como a BNCC traz à cena a discussão curricular, que ganha feições instrumentais de planejamento, adequação e adaptação; enquanto a esfera decisória se afasta do fazer curricular, os conhecimentos são definidos pela BNCC e cabe ao currículo organizar sua exequibilidade.

Refutando tal posição, Lopes (2015) fala da ameaça de coisificação do currículo quando se antevê a possibilidade de definição prévia que restringe a luta política e elimina as articulações contingenciais. A autora, numa leitura que assumidamente não tem intenção de contrapor-se na apresentação de proposta alternativa, mas busca "problematizar seus enfoques, provocar outras possibilidades de pensar, conceber outras formas de objetivar/subjetivar, desestabilizar discursos...” (p. 137), defende então um currículo sem fundamento na compreensão de que

não considera possível sustentar nenhuma dessas lutas com base em critérios universais e imperativos categóricos, não submetidos às lutas contingentes pela significação. [...] Propostas e normas não têm os supostos alicerces 
epistemológicos sólidos, capazes de serem justificados fora da luta política que se remete às condições de existência de todos nós (Lopes, 2015, p. 140).

E essa luta por significação é ela mesma produção cultural, se move no terreno da cultura, também compreendida como discursiva. Laclau (2015) afirma ser a cultura o campo onde esses deslocamentos operam. Vendo-a como questão discursiva, o deslocamento se dá de uma reflexão epistemológica a uma prática discursiva; cultura não como objeto empírico que se dá a conhecer, mas problema de enunciação, daí que as afirmações culturais são postas num jogo de autorização, diferenciação, reinscrição que se articula em lugares não demarcados com precisão que permite afirmá-los como o melhor, adequado, mas circulam numa zona de instabilidade onde o significado último nunca está dado e garantido, mas articula-se em lugares híbridos que desestabilizam essencialismos. Daí o argumento que tenho defendido: a compreensão de política curricular como política cultural.

Essa perspectiva rasura o espaço de uma polarização binária entre conhecimento e cultura e se afasta da ideia do bom objeto empírico, pois não se trata de diversos conhecimentos que permitem seletivamente acessar o que há de melhor, relegando os outros a um lugar secundário.

Penso que esse é o ponto nevrálgico da discussão posta: a noção de conhecimento assentada numa perspectiva de antagonismo lato - de que não há pontos de contato e que um polo rejeita e exclui o outro, na impossibilidade de partilhar qualquer elemento. Retomando a perspectiva de Laclau, seria possível pensar num outro sentido de antagonismo - não apenas de uma relação de exclusão, mas de complementariedade, uma vez que o antagonismo é a possibilidade de uma formação discursiva, bem como sua impossibilidade de fechamento total, de uma objetividade plena. Nesse sentido, podemos pensar, com Mouffe (1999), numa relação agônica para o conhecimento?

Em termos políticos, na relação agônica a categoria de inimigo é substituída pela de adversário, uma vez que o espaço comum entre adversários reside justamente na aceitação da disputa política em um espaço discursivo democrático pluralista (Mendonça, 2003, p. 139).

Como em Mouffe (1999), uma relação agônica nesse sentido não implica objetar a importância e a relevância dos conhecimentos científicos, nem sua descaracterização, mas também não significa que considerar diferentes conhecimentos pleiteia a negação dos conhecimentos científicos. Nessa linha, a questão que precisa ser observada é que ao enfatizar os conhecimentos científicos têm se seguido um percurso também de polarização entre ciência e cultura.

Em diálogo com Bhabha (2003), assumo o conhecimento na sua condição de enunciação e que esta se dá na/com a diferença cultural, na condição de significar do outro que abala uma autoridade colonial que se institui na dualidade que permite definir o que é verdadeiro/falso, positivo/negativo. $\mathrm{O}$ autor convoca a pensar para além dessa polaridade, 
num espaço intervalar que, nem um nem outro, erige uma temporalidade do interstício, da ambivalência que exige negociação.

A noção de negociação em Bhabha é cara e alinhava sua trama discursiva na defesa que faz desse "para além" de posições binárias: diferindo da dialética hegeliana, a negociação mantém em suspenso os antagonismos, as disputas e os conflitos que não são superados, mas se mantém em articulações provisórias em que o fechamento total é impossível; trata-se de fechamentos contingenciais num terreno de indecidibilidade: movimentos em que o fechamento não garante completude - ao contrário, implica precariedade a partir do fluxo e contestação da significação diferencial. Essa impossibilidade de fechamento total, nos movimentos deslizantes de significação, evidencia também a condição de que os "termos" postos em negociação não têm uma imutabilidade, uma anterioridade essencial, ainda que, a partir da leitura de Bhabha (2003) se possam observar estratégias na tentativa de regular, normalizar a diferença, no engendramento de um discurso colonial.

Nesses termos, Bhabha discute os tropos que sustentam esse discurso e afirma que ele se erige a partir da fixidez, numa representação paradoxal que oscila da ordem imutável à repetição demoníaca. E na ambivalência desse processo, que é central para a análise da construção de um discurso colonial e suas estratégias, o autor apresenta o estereotipo como fetiche. Trago essa questão para, de forma diferente de Young, pensar o conhecimento: conhecimento poderoso como estereótipo.

O estereótipo se articula na ambivalência, o que permite trazer a sua leitura nos termos do fetiche. Na discussão a que Bhabha alude, não se trata de identificar o estereótipo em si, como reconhecimento de imagens normatizantes, mas de compreender essa ambivalência e daí observar a produtividade desse discurso, numa leitura que permita então transgredir essas fronteiras. O estereótipo se funda no reconhecimento/repúdio das diferenças, na tensão entre desejo e fobia, na problemática reinstaurada pela ansiedade da fantasia e a normalização dessa perturbação no objeto de fetiche.

Ao trazer a proposição de Bhabha da análise do discurso colonial para discutir conhecimento, alinho-o à perspectiva de que ele é reificado cotidianamente no contexto da prática; assim ele se faz representante no contexto escolar de uma produção estrangeira a ela. Como fetiche, oscila entre a repulsa do conhecimento a partir das críticas postas ao mesmo tempo que enceta o desejo, opção que faz com que sejam defendidas, tendo em vista suas possibilidades de organização do currículo, de materializar no cotidiano o currículo.

Na verdade, explorar essa ambivalência que opera no âmbito da visão do conhecimento objetificado e fetichizado permite discutir sua condição como produção cultural, como discurso, e aí apaga-se o lugar original de produção, fragiliza as fronteiras delimitadoras e fixas do que é visto "próprio" e evidencia a condição de jogo político-discursivo dessa produção.

Assumir tais perspectivas significa "indagar a produção discursiva daqueles que falam a partir de um entre-lugar discursivo que desafia noções estreitas de língua, nação, história” (Pagano, 2000, p. 159). Ao fazer essa ressalva, destaco o que chamei de colonização a 
partir de dentro. Opero aqui, no diálogo com Bhabha, com referenciais pós-coloniais, mas que não se limitam à possibilidade de análise de contextos marcados pela colonização, remetendo a uma história superada, mas permitem problematizar as assimetrias dentro do espaço nacional. O autor permite discutir a questão da colonização para além da invocação da imagem da dominação, mas sim em deslocamentos não só físicos como deslocamentos discursivos que alinham estratégias de articulação de uma autoridade colonial, uma autoridade que se pretende erigir como verdadeira.

Esses processos não são lineares; ao contrário, são imprevisíveis ao mobilizar as constantes rearticulações discursivas tanto daquilo que se pretende hegemônico como dos outros que confrontam essa pretensão. É essa tensão que mantém aberta a significação e que expõe a precariedade e contingência desse processo; ela mina a ideia de autoridade irrefutável no atravessamento do que Bhabha chama de terceiro espaço - uma zona discursiva que não pertence nem a um nem a outro e, paradoxalmente, um entre-lugar intervalar que negocia com a alteridade e abala a autoridade ao demonstrar que a coerência e a universalidade a ela aludida são precárias, ela também é inacabada e se monta e desmonta a partir das necessidades de exercer seu poder.

Retomando a metáfora dos padrões e de seus usos no processo de colonização, Seed (1999), nas análises sobre isso, afirma que o intento colonizador teve grande força coesiva, pois exigiu um processo de homogeneização daqueles que aportaram no Novo Mundo: uma simplificação linguística, um sistema jurídico comum, ou seja, o investimento em tornar comum para assegurar a ascendência sobre a terra e aí inventar uma identidade “inglesa” ou "espanhola” ou "portuguesa”.

O comum relaciona-se a uma violência, uma força tornada legítima na garantia de propriedade e prioridade. É essa dimensão que parece subsumida na defesa do "melhor para todos” que se tenta tornar comum, que silencia e bloqueia os espaços de negação, contestação que mantém a negociação em aberto a partir do direito de significar do outro/diferente - para me valer do mesmo argumento poderoso que vem marcando a discussão.

A defesa do direito à significação implica o reconhecimento de que, ao se engendrar um caminho de unificação, centralização do que se ensina, do que é a escola, opera-se uma colonização a partir de dentro, o estabelecimento de política-padrão que inventa um "nacional” unificado, apagando diferenças, antagonismos, incomensurabilidades. Não há o que negociar: o padrão estabelece quem, com precisão, é capaz de, a partir da leitura desse novo céu, localizar o Novo Mundo.

Se observar a questão do conhecimento em termos de direitos - tal como a noção de direito à aprendizagem sublinha - é caminho para alcançar justiça e democracia, penso que um espaço democrático é aquele em que o investimento está não em obstruir, mas em fomentar a luta política, em que a exterioridade não apague a multiplicidade da interioridade. 


\section{Notas}

1. O mote de construção deste texto remete à visita, durante atividade acadêmica em Portugal, ao Portugal dos Pequenitos, parque que foi inaugurado em 8 de junho de 1940 na cidade de Coimbra. Integra desde 1959 a Fundação Bissaya Barreto, que tem como patrono o professor que foi também o idealizador do parque. Em seu site afirma que se trata de "Retrato vivo da portugalidade e da presença portuguesa no mundo, o Portugal dos Pequenitos é ainda hoje um referencial histórico e pedagógico de muitas gerações. Para além de ser um espaço de aproximação de culturas e de cruzamento entre povos, o Portugal dos Pequenitos é também uma mostra qualificada da arte escultórica e arquitetónica que, pela miniatura e pela minúcia, ainda hoje encantam crianças, jovens e adultos”. Lá é possível, na apresentação da história de Portugal às crianças, ver reproduções de Padrões do Descobrimento com o descritivo que mostra o uso desses marcos como indicação de propriedade e prioridade sobre o território a que ser aportou. Imagens fotográficas que constam do acervo pessoal da pesquisadora. Disponível em: http://www.fbb.pt/pp/o-parque/historia/ Acesso em jun. 2019.

2. Dados disponíveis no site do Instituto do Patrimônio Histórico e Artístico Nacional. Ver: http://portal.iphan.gov.br/pagina/detalhes/329/; http://portal.iphan.gov.br/pagina/detalhes/1458. Acesso em: set. 2019. Há outros no Brasil, como em Porto Seguro/BA e Laguna/SC.

3. Optou-se, para construção da análise e argumentação do texto, pela utilização do texto não só da BNCC homologada, mas também de suas versões preliminares. Tal estratégia permite observar o desenvolvimento e o adensamento da lógica de centralização curricular assentada na qualificação do conhecimento e determinação do que é considerado essencial.

\section{Referências bibliográficas}

BASTOS, Maria Malvina. As Grandes Navegações Portuguesas e a conquista das águas profundas pelo Brasil. Economia \& Energia, ano XVI, nº 87, out./dez. 2012.

BRASIL. Base Nacional Comum Curricular. Brasília: Ministério da Educação, 1ª versão, 2015. Base Nacional Comum Curricular. Brasília: Ministério da Educação, 2ª versão, 2016.

Base Nacional Comum Curricular. Brasília: Ministério da Educação, $3^{\mathrm{a}}$ versão, 2017.

Base Nacional Comum Curricular. Brasília: Ministério da Educação, 2018.

FRANGELLA, Rita de Cássia. Currículo Como Local Da Cultura: por outras enunciações curriculares. In: FRANGELLA, Rita de Cássia (Org.). Currículo, formação e avaliação: redes de pesquisas em negociação. Curitiba: CRV, 2016a. p. 15-36.

Um pacto curricular: Pacto Nacional pela Alfabetização na Idade Certa e o desenho de uma base comum. Educação em Revista, v.32, p. 69-89, 2016b.

Entre o comum e o singular; entre direito e justiça - problematizando políticas curriculares. In: Currículo entre o comum e o singular. Recife: Anpae, 2018. p. 320-338.

KALIL, Luis Guilherme; FERNANDES, Luiz Estevam. Entrevista com Patrícia Seed. História Unisinos, v. 18(2), maio/ago. 2014.

LOPES, Alice Casimiro. Por um currículo sem fundamentos. Linhas Críticas, Brasília, v. 21, n. 45, p. 445466, maio/ago. 2015.

MENDONÇA, Daniel de. A noção de antagonismo na Ciência Política contemporânea: uma análise a partir da perspectiva da Teoria do Discurso. Revista de Sociologia e Política, Curitiba, v. 20, p. 135-145, jun. 2003.

MOUFFE, Chantal. El retorno de lo politico - comunidad, ciudadanía, pluralism, democracia radical. Barcelona: Paidós, 1999. 
PESSOA, Fernando. Mensagem - edição especial comemorativa do $75^{\circ}$ Aniversário da morte de Fernando Pessoa. Famalicão: Centro Atlântico, 2010.

SEED, Patrícia. Cerimônias de posse na conquista do novo mundo (1492-1640). São Paulo: Editora Unesp, 1999.

VYGOTSKY, L. S. Pensamento e Linguagem. São Paulo: Martins Fontes, 1993.

\section{Correspondência}

Rita de Cassia Prazeres Frangella: Doutora em Educação. Professora associada da Faculdade de Educação da Universidade do Estado do Rio de Janeiro. Programa de Pós-Graduação em Educação Proped/UERJ, Cientista do Nosso Estado/FAPERJ e Bolsista de Produtividade em Pesquisa - CNPq.

E-mail: rcfrangella@gmail.com

Texto publicado em Currículo sem Fronteiras com autorização da autora 